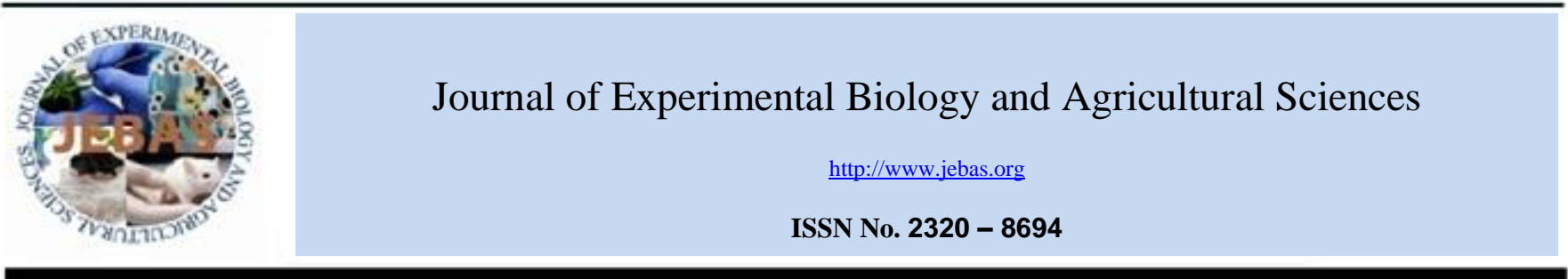

\title{
DICKKOPF-1 SERUM LEVELS IN SAUDI BOYS WITH CEREBRAL PALSY AND CORRELATIONS WITH BODY MASS INDEX AND BONE TURNOVER MARKERS
}

\author{
Zahra Ali AL-Balawi ${ }^{1}$, Hala Salim. Sonbol ${ }^{2 *}$ \\ ${ }^{1}$ Department of Biochemistry, Faculty of Science, University of Tabuk, P.O. Box No. 741, Tabuk, 71491, Kingdom of Saudi Arabia. \\ ${ }^{2}$ Department of Biochemistry, Faculty of Science, King Abdul Aziz University, 2599 Ahmad ibn qadim-ash shati, UnitNo:1, Jeddah 23513-6886, Kingdom of Saudi Arabia.
}

Received - August 23, 2018; Revision - September 29, 2018; Accepted - October 03, 2018

Available Online - October 5, 2018

DOI: http://dx.doi.org/10.18006/2018.6(5).862.870

\author{
KEYWORDS \\ Bone turnover markers \\ Cerebral palsy \\ Children \\ Dickkopf-1 \\ Physical disabilities
}

\begin{abstract}
Cerebral palsy (CP) is a common disorder in children. Dickkopf-1 (Dkk1) inhibits the canonical Wnt signaling pathway. The study aimed to assess the serum levels of Dkk1 in boys with $\mathrm{CP}$ and to evaluate its correlations with body mass index (BMI) and bone turnover markers (BTMs).This study included 32 Saudi boys with different physical disabilities as a result of CP and muscular dystrophy and 39 healthy Saudi boys were enrolled as a control group. The serum levels of Dkk1, N-terminal propeptide of type I collagen (P1NP), bone alkaline phosphatase (B-ALP), and C-terminal cross-linking telopeptide of type I collagen ( $\beta$-CTX) were measured using enzyme link immunosorbent assay (ELISA) kits. Serum Dkk1 levels were higher in boys with CP than in controls. Further, level of PINP, TSH, FT4, calcium, and phosphorus were also reported significantly higher in CP boys than in controls. While, level of BMI, $\beta$ CTX, 25-hydroxyvitamin D and PTH were significantly lower in patients than in controls. Serum Dkk1 levels were moderately correlated with calcium $(r=0.361, P=0.0240)$ in the controls. Dkk1 may play a role in bone loss in boys with $\mathrm{CP}$ experiencing weight loss. Dkk1 could aid in the assessment of boys with $\mathrm{CP}$ and abnormal bone turnover.
\end{abstract}

* Corresponding author

E-mail: hsunbol@kau.edu.sa (Hala Salim Sonbol)

Peer review under responsibility of Journal of Experimental Biology and Agricultural Sciences.

Production and Hosting by Horizon Publisher India [HPI] (http://www.horizonpublisherindia.in/).

All rights reserved.
All the article published by Journal of Experimental Biology and Agricultural Sciences is licensed under a Creative Commons Attribution-NonCommercial 4.0 International License Based on a work at www.jebas.org.

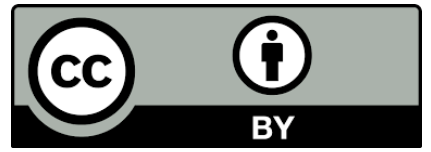




\section{Introduction}

The Dickkopf (Dkk) family is a Wnt signaling pathway antagonist that has many roles in human physiological and pathological processes through both Wnt pathway-dependent and Wnt-independent mechanisms (Shao et al., 2017).This gene family encodes secreted glycoproteins that are composed of five members: Dkk1-4 and Dkkll (soggy) (Choi et al., 2012). The Dkk family has a master role in bone regulation (Ray et al., 2017). Dkk1decreases bone formation and increases bone resorption by inhibiting $\mathrm{Wnt} / \beta$ catenin signaling through the formation of a tertiary complex with a low density lipoprotein receptor-related protein, LRP 5 and 6, and kermen 1 and 2 receptors (Niida et al., 2004). Therefore, high serum Dkk1 is associated with a decrease in bone mass and density (Butler et al., 2010; Tella \& Gallagher, 2014). The Dkk1 protein is encoded by the Dkk1 gene. In humans, the Dkk1 gene is located on chromosome 10 (10q11.2) (Roessler et al., 2000). Dkk1 is believed to be expressed in a wide variety of human tissues including bone tissue; Dkk1 is primarily expressed by osteocytes (Bonewald, 2011). The chromosomal region containing the Dkk1 gene has been associated with the regulation of bone mass in men (Ralston et al., 2005). Morvan and colleagues proved that Dkk1 expression in vitro negatively affects bone formation by inhibiting osteoblast differentiation and inducing adipocyte differentiation (Morvan et al., 2006).

In bone tissue, osteocytes are the most sensitive bone cells to mechanical load. Osteocytes respond to mechanical load by producing a signaling molecule called Wnt that activates the canonical Wnt signaling pathway, inducing bone formation (Bonewald \& Johnson, 2008; Santos et al., 2009; Klein-Nulend et al., 2013). The canonical Wnt/ $\beta$-catenin signaling increases bone mass by inducing the differentiation of osteoblasts (Galli et al., 2012). However, the absence of mechanical load in cases of bed rest, disused limbs, and microgravity increases bone loss due to the apoptosis of osteocytes and osteoblasts, while osteoclast activity increases as a result of increased Wnt signaling antagonist expression (Aguirre et al., 2006; Robling \&Turner, 2009). Additionally, mechanical load causes a significant reduction in Wnt signaling antagonists, such as sclerostin and Dkk1 (Holguin et al., 2016).

Childhood and adolescence are important periods for bone mineralization. Although peak bone mass and bone mineral density (BMD) are primarily determined genetically, they are also related to age, weight, height, nutrition, physical activity, hormones, drugs, and environmental factors related to lifestyle (Baroncelli et al., 2005; Goksen et al., 2006; Verrotti et al., 2010). The Ministry of Health in Saudi Arabia has reported 1.5 million people with disabilities (Ministry of Health Saudi Arabia, 2016).
Cerebral palsy (CP) is a clinical syndrome caused by nonprogressive disorders in the development of the brain. CP is the most common form of chronic motor disability in children (Aronson \&Stevenson, 2012). Children with severe CP are at risk for developing low BMD and low-impact fractures due to the restriction of mobilization and paralysis of their limbs, which increases bone resorption and reduces bone mass and size (Lin \& Henderson, 1996; Unay et al., 2003; Aronson \&Stevenson, 2012).

Bone turnover markers (BTMs) are used to assess bone metabolism. BTMs are molecules released from bone cells during bone metabolism and are used with limitations as a diagnostic tool in osteoporosis (Civitelli et al., 2009). They can also predict rapid bone loss in clinical studies and monitor drug efficacy during healing of fractures (Henriksen et al., 2015). BTMs are classified into bone formation markers and bone resorption markers (Szulc \& Delmas, 2008). Many hormones and minerals, including parathyroid stimulating hormone (PTH), thyroid stimulating hormone (TSH), glucocorticoids, calcium, phosphorus and vitamin D, affect bone mass. In addition, external factors influence bone such as physical activity, sun exposure, and nutrition (Hunter et al., 2001; Quarles, 2008).

Currently, there is no information on protein biomarkers and their relation to physical disabilities specifically in boys with CP. To our knowledge, this study is the first to analyze the serum levels of Dkk1 and address the relationship between Dkk1 and different measured parameters and mechanical loading in physically disabled boys in Saudi Arabia. We decided to address the role of Dkk1 as a potential protein biomarker in boys with $\mathrm{CP}$ due to its key role in bone regulation. Our hypothesis was that Saudi boys with diverse physical disabilities with increased serum Dkk1levels have a greater risk for osteoporosis and osteoporosis-related fractures. The aim of this study was to determine the serum levels of Dkk1 in Saudi boys with $\mathrm{CP}$ and to study the correlation between serum Dkk1 levels and BMI as well as BTMs (P1NP and CTX).

\section{Materials and methods}

\subsection{Study subjects}

Thirty-two (32) Saudi boys (5-12 years old) with diverse physical disabilities, such as hemiplegia and quadriplegia, as a consequence of $\mathrm{CP}$ and muscular dystrophy, were involved in this cross-sectional study over a period of 18 months (March 2013 to September 2014). They were recruited from the Disabled Children's Association in Jeddah, Kingdom of Saudi Arabia. Thirty-nine (39) healthy Saudi volunteers, age and sex matched with the patients, were employed as a control group from the 
Center of Excellence for Osteoporosis Research (CEOR) at King Fahad Center for Medical Research (KFCMR), King Abdulaziz University (KAU), Jeddah, Kingdom of Saudi Arabia. Written consent to participate in the study was obtained from each child's guardian. This research was approved by the Human Research and Ethics Committee at CEOR, KAU, Jeddah, Kingdom of Saudi Arabia. Children with chronic illnesses, such as renal diseases, liver diseases, thyroid disorders and diabetes mellitus, or those on medications that affect bone metabolism, such as steroids and antiepileptic medications, were excluded from the study.

\subsection{Anthropometric measurements}

Height and body weight measurements were recorded. The weight was measured by a Seca Digital Chair (Seca GmbH \&Co, Germany), a special medical scale designed to measure the weight of physically disabled patients. Height was measured by using a tape measure while the children were lying on a bed. BMI was calculated as weight $(\mathrm{kg}) /$ height $\left(\mathrm{m}^{2}\right)$.

\subsubsection{Blood sample collection}

Venous blood samples were randomly collected. Immediately, serum was separated and stored at $-80^{\circ} \mathrm{C}$ until further use. All samples were stored in tubes labeled with the ID number of the participants.

\subsubsection{Biochemical analysis}

Serum Dkk1 levels were measured as described by AL-Balawi et al. (2017) by enzyme immunoassays (Betts et al, 2010) according to the manufacturer's instructions (Enzo Life Sciences AG, Switzerland). The optical density was read at $450 \mathrm{~nm}$ using a microplate reader (ELx 808, Bio Tek. USA). The result was calculated using linear graph paper, and the average optical reading for each standard versus Dkk1 concentration was plotted. The serum concentrations of PINP and $\beta$-CTX were measured (Ardawi et al., 2010) by electrochemiluminescence immunoassays (ECLIAs) using an Elecsys E411 autoanalyzer (Roche Diagnostics GmbH, D-68298, Mannheim, Germany). TSH and thyroxin hormone were determined by Vitros ECI (Immunodiagnostic Systems, UK). PTH was measured using an ECLIA Elecsys autoanalyzer (Roche Diagnostics $\mathrm{GmbH}$, Sand hofer Strasse 116, D-68305, Mannheim, Germany).The assessment of 25-hydroxyvitamin D [25(OH)D] (Ardawi et al., 2010) was conducted using chemiluminescent immunoassay (CLIA) technology for the quantitative determination of $25(\mathrm{OH}) \mathrm{D}$ and other hydroxylated vitamin $\mathrm{D}$ metabolites in human serum, and the assay was performed using the LIAISON fully automatic immunoassay system analyzer. Serum calcium phosphate and bone alkaline phosphatase (B-ALP) were assessed using the Vitros slide method with a Vitros 250 Chemistry System autoanalyzer (Ortho-Clinical DiagnosticsJohnson \& Johnson Co., USA).

\subsection{Statistical analysis}

Statistical analyses were performed by using the Statistical Package for Social Science package (Version 20, SPSS INC., Chicago, Illinois, USA). Descriptive data are given as the median (interquartile range). Mann-Whitney tests were used to compare patients and controls. Correlations between different variables and Dkk1 were assessed using Pearson's correlation as appropriate. A $P$ value $<0.05$ was considered significant.

\section{Result}

3.1 Comparison of the physical and biochemical characteristics of the control and $\mathrm{CP}$ boys

The comparison between the control and CP boys is presented in Table 1 . There were no significant differences in age $(P=0.986)$. The BMI of CP boys was significantly lower than that of the control group $(P=0.016)$. Further, $\mathrm{CP}$ boys had a higher median Dkk1 level (177719pg/mL) than control boys $(15292 \mathrm{pg} / \mathrm{mL})$. However, this increase was not significant $(P=0.234)$. With regard to the bone formation markers, P1NP was significantly increased $(P=0.0001)$, while $\beta$-CTX was significantly decreased in CP boys compared with control boys $(P=0.0001)$. The bone formation marker B-ALP showed no differences between patients and controls. According to the data, both PTH and 25(OH)D levels were obviously significantly higher in the control boys than in the CP boys ( $P=0.0001$ for both). TSH, FT4, calcium and phosphate serum levels were significantly higher in CP boys than in control boys ( $P=0.0001, P=0.0001, P=0.0001$ and $P=0.002$, respectively).

\subsection{Correlations between Dkk1 and measured parameters}

Serum levels of Dkk1 had a positive moderate correlation with calcium in controls group $(\mathrm{r}=0.361, \mathrm{P}=0.024)$. Moreover, there were weak negative correlations identified between Dkk1, $\beta$-CTX, $(\mathrm{r}=-0.133, \mathrm{P}=0.420)$, PTH $(\mathrm{r}=-0.199, \mathrm{P}=0.225)$ and phosphate $(\mathrm{r}=-$ $0.137-0.199 \mathrm{P}=0.405)$. However, did not reach significance value.

Weak correlation was also demonstrated between Dkk1 and and PINP ( $r=0.332, P=0.063), \beta-C T X(r=0.155, P=0.397), B-A L P$ $(\mathrm{r}=0.270, \quad \mathrm{P}=0.135), \operatorname{TSH}(\mathrm{r}=0.123, \mathrm{P}=0.502)$ and phosphate $(\mathrm{r}=0.259, \mathrm{P}=0.152)$ in patients group. This correlation did not reach significance values.BMI $(r=-0.219, P=0.229)$ was negatively weakly correlated to Dkk1 in patients group.

\section{Discussion}

A comparison between boys with $\mathrm{CP}$ and control boys showed that the BMI in CP boys was significantly lower than that in the control boys $(P=0.016)$. Low BMI and underweight in boys with $\mathrm{CP}$ in our study could be a consequence of feeding problems resulting either from the children's pathological symptoms 
Table 1Comparison between the physical and biochemical characteristics of patients and control boys

\begin{tabular}{|c|c|c|c|}
\hline Variables & $\begin{array}{l}\text { Controls } \\
(\mathrm{n}=39)\end{array}$ & $\begin{array}{c}\text { Patients } \\
(\mathrm{n}=32)\end{array}$ & $\begin{array}{l}P \text { value using Mann- } \\
\text { Whitney Utests }\end{array}$ \\
\hline Age (years) & $8.00(7.00-9.50)$ & $8.00(7.00-9.00)$ & 0.986 \\
\hline BMI $\left(\mathrm{kg} / \mathrm{m}^{2}\right)$ & $16.84(16.15-18.05)$ & $15.63(13.98-17.19)$ & 0.016 \\
\hline Dkk1 (pg/mL) & $15291.92(13263.40-17518.15)$ & $177719.00(11772.50-26396.25)$ & 0.234 \\
\hline PINP (ng/mL) & $328.00(294.00-401.00)$ & $548.90(460.90-712.45)$ & 0.0001 \\
\hline$\beta-\mathrm{CTX}(\mathrm{pg} / \mathrm{mL})$ & $888.00(811.00-949.00)$ & $438.30(248.55-604.30)$ & 0.0001 \\
\hline B-ALP (U/L) & $213.00(199.00-231.00)$ & $231.50(196.75-264.75)$ & 0.252 \\
\hline 25(OH)D (nmol/L) & $49.10(44.80-60.13)$ & $29.00(19.13-37.13)$ & 0.0001 \\
\hline PTH (pmol/L) & $4.05(3.66-4.58)$ & $1.36(0.70-2.16)$ & 0.0001 \\
\hline TSH (uIU/mL) & $1.98(1.79-2.16)$ & $3.04(2.01-4.58)$ & 0.0001 \\
\hline FT4 (pmol/L) & $10.23(9.02-11.11)$ & $18.48(16.50-20.20)$ & 0.0001 \\
\hline Calcium (mmol/L) & $2.40(2.36-2.41)$ & $2.62(2.39-2.70)$ & 0.0001 \\
\hline Phosphate (mmol/L) & $1.39(1.30-1.45)$ & $1.65(1.39-1.92)$ & 0.002 \\
\hline
\end{tabular}

Data are represented as the median (interquartile range). P values were calculated using Mann-Whitney Utests. BMI: body mass index; PINP: total procollagen type 1 amino-terminal propeptide; $\beta$-CTX: C-terminal cross-linking telopeptide of type I collagen. PTH: Parathyroid hormone, 25(OH)D: 25-hydroxyvitamin D, TSH: thyroid stimulating hormone, FT 4 : thyroxine,B-ALP:alkaline phosphatase

Table 2Pearson's correlation between Dkk1 (pg/mL) level and measured variables in controls and CP patients

\begin{tabular}{|c|c|c|c|c|}
\hline \multirow{2}{*}{ Variables } & \multicolumn{2}{|c|}{ Controls Dkk1 } & \multicolumn{2}{|c|}{ Patients Dkk1 } \\
\hline & $\mathrm{R}$ & $P$ & $\mathrm{R}$ & $P$ \\
\hline Age (years) & -0.076 & 0.647 & -0.039 & 0.832 \\
\hline BMI $\left(\mathrm{kg} / \mathrm{m}^{2}\right)$ & -0.080 & 0.629 & -0.219 & 0.229 \\
\hline PINP (ng/mL) & 0.003 & 0.984 & 0.332 & 0.063 \\
\hline$\beta-\mathrm{CTX}(\mathrm{pg} / \mathrm{mL})$ & -0.133 & 0.420 & 0.155 & 0.397 \\
\hline B-ALP (U/L) & 0.044 & 0.793 & 0.270 & 0.135 \\
\hline $25(\mathrm{OH}) \mathrm{D}(\mathrm{nmol} / \mathrm{L})$ & 0.208 & 0.204 & -0.160 & 0.381 \\
\hline PTH (pmol/L) & -0.199 & 0.225 & -0.152 & 0.407 \\
\hline TSH (uIU/mL) & 0.055 & 0.738 & 0.123 & 0.502 \\
\hline FT4 (pmol/L) & -0.010 & 0.951 & 0.026 & 0.886 \\
\hline Calcium (mmol/L) & 0.361 & 0.024 & 0.101 & 0.584 \\
\hline Phosphate $(\mathrm{mmol} / \mathrm{L})$ & -0.137 & 0.405 & 0.259 & 0.152 \\
\hline
\end{tabular}

$R$ : Pearson's correlation (weak correlation if $R<0.3$, moderate correlation if $0.3<R<0.7$, strong correlation if $R>0.7$ ). PINP: total procollagen type 1 amino-terminal propeptide. $\beta$-CTX: C-terminal cross-linking telopeptide of type I collagen. BMI: Body mass index. 
associated with CP or the subjects being in a household with multiple children, which could lead to a decreased ability to manage the disease. In this respect, children with $\mathrm{CP}$ are often viewed as undernourished and believed to show growth impairment (Melunovic et al., 2017). Diwan et al. (2014) analyzed the BMI of 50 children (1-18 years old) with different clinical types of $\mathrm{CP}$ with respect to their gross motor functions using a gross motor function classification system. The researchers concluded that underweight is prevalent in children with spastic quadriplegic CP. They stated that poor nutrition in $\mathrm{CP}$ children is the result of various factors that directly or indirectly affect food intake, such as oro-motor dysfunction and/or poor appetite (Diwan et al., 2014). Feeding problems are common in children with CP (Dahl et al., 1996). Disabled children or children who required an aid to walk also had a greater chance of having eating and swallowing problems, thus needing food mashing or liquidization than those who were not disabled (Sullivan et al., 2000). Moreover, children suffering from CP also had medical and social issues, restricting their participation in physical activities (Azcue et al., 1996).

However, conflicting studies have shown that children with $\mathrm{CP}$ have a high rate of overweight, mostly among ambulatory children (Hurvitz et al., 2008). Duran et al. (2018) reported that the prevalence of excess body fat in CP children was $17.0 \%$. Other researchers studied 348 boys and 240 girls with a mean age of 11.2 (standard deviation 3.2) years (Pascoe et al., 2016) and stated that $19.4 \%$ of ambulant CP children were overweight or obese due to reduced physical activity (Pascoe et al., 2016). The BMI of CP children and adolescents $(n=73)$ of different genders, with a median age of 9.6 years (range 2.6 to 19.4), was measured in a study conducted by Delalić et al. (2014). Twenty-nine percent of the participants were under weight and were found to have quadriplegia. The rest of the participants who were overweight (11\%) and obese $(9.6 \%)$ had diplegia. Approximately $40 \%$ of children and adolescents with $\mathrm{CP}$, were shown to have nutritional problems. Delalić et al. (2014) stated that immobile children and those with quadriplegia have an increased risk for malnutrition, whereas mobile children and those with diplegia $\mathrm{CP}$ have an increased risk for over nutrition (Delalić et al., 2014).

This study showed that serum levels of Dkk1 in boys with CP were nonsignificantly higher than those in the controls. Similar results were achieved in our previously published research, indicated that the serum Dkk1 levels in the physically disabled girls were significantly higher than control girls (AL-Balawiet al., 2017). In this respect, Ke et al. (2012) reported that Dkk1 serum levels were increased in patients with bone diseases. A study conducted by Dovjak et al. (2014) demonstrated that Dkk1 levels increased with age and in patients with hip fractures. Significant increases in Dkk1 in cases of mechanical unloading were observed in immobilized men with spinal cord injury (Gifre et al., 2015). Moreover, a study on rodents showed that mRNA expression of Dkk1 was upregulated in fracture healing, and the levels peaked around the $14^{\text {th }}$ post-traumatic day ( $\mathrm{Li}$ et al., 2011). Butler and colleagues also stated that the over expression of Dkk1 was inversely proportional to bone mass and associated with metabolic bone disease (Butler et al., 2010). Dkk1 contributes to bone lesions by impairing osteoblast activity (Rachner et al., 2014).

In the present study, serum levels of the bone formation markers $\mathrm{P} 1 \mathrm{NP}$ and B-ALP were significantly higher, while $\beta$-CTX levels were significantly lower in boys with $\mathrm{CP}$ than in controls. The mechanical loading created by physical therapy could explain the high levels of P1NP and B-ALP and the low level of $\beta$-CTX in boys with $\mathrm{CP}$. This finding indicates that bone collagen synthesis in mature osteoblasts is diminished by rapid unloading in young people. The BTMs could be affected by prolonged wheelchair use in boys with $\mathrm{CP}$ but not in their counterparts. Therefore, no matter how consistent the performance of physical activity is, alterations in the levels of bone formation markers are very likely (ALBalawi et al., 2017). In children, bone turnover can be 10 times higher than that in adults due to three physiologic processes related to the skeleton: bone modeling, remodeling, and growth. The levels of bone formation and resorption markers are consequently much higher in children than in adults (Rauchenzauner et al., 2007). A study was performed by

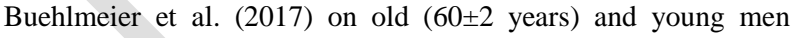
( $23 \pm 3$ years) who experienced bed rest for 14 days. There were higher P1NP levels in young men than in old men $(P<0.001)$, but these levels decreased during bed rest in the young group $(P<0.001)$ (Buehlmeier et al., 2017). The increase in bone resorption markers during bed rest was comparable among the age groups. Greater urinary $\beta$-CTX levels at baseline were observed in young than in old subjects, while the increases during unloading or bed rest were similar. The authors concluded that during bed rest, bone formation markers were reduced only in young men, whereas resorption markers were elevated to a comparable extent. The researchers suggested that older men did not have a higher risk of losing bone when immobilized (Buehlmeier et al., 2017). Furthermore, a study conducted in postmenopausal women demonstrated that PINP but not $\beta$-CTX was significantly associated with the level of physical activity (Adami et al., 2008). According to Adami, PINP could be more sensitive to the mechanical load than Dkk1 and $\beta$-CTX.

In the current study, the serum levels of vitamin D in boys with $\mathrm{CP}$ were significantly lower than those in the controls, and calcium levels were significantly higher than those in the controls. The same results were reported by others in patients with physical disabilities (Sato et al., 1998). Calcium is an essential mineral for babies and young children to ensure the 
growth of strong bones. In addition, vitamin D plays a vital role in calcium metabolism and bone mass during growth and development (Henderson et al., 2002). However, children with physical disability lack calcium and vitamin D due to feeding problems and may have less exposure to sunlight than healthy children due to their prolonged wheelchair use, which limits their accessibility and ability to go outdoors (Henderson et al., 2002; Hillesund et al., 2007; Dahlseng et al., 2012). Accordingly, this status could contribute to poor bone mineralization. Studies conducted in Kingdom of Saudi Arabia showed that the Saudi population has a low level of vitamin D due to lifestyle and inadequate exposure to sunlight during the day (Mansour \& Alhadidi, 2012). In this study, the increase in serum calcium level could be due to a low degree of calcium incorporation in the skeleton of physically disabled patients as result of decreased bone mineralization as well as increased bone resorption markers that release calcium from bone storage.

Serum PTH levels in the present study were significantly lower in $\mathrm{CP}$ patients than controls. In this regard, a study was performed with 16 boys and 8 girls (aged 10 months to 12 years) and showed that PTH levels were similar in CP patients and controls (Tasdemir et al., 2001). Moreover, others have indicated that PTH levels in $\mathrm{CP}$ patients depend on ambulatory status; thus, patients with nonambulatory $\mathrm{CP}$ showed lower PTH levels than patients with ambulatory CP (Kim et al., 2015; Shin et al., 2017). The increase in the calcium level may be responsible for the significant low levels of PTH observed in our patients by a negative feedback mechanism.

According to our results, the level of T4 hormones was significantly higher in patients than in controls. Similar results were achieved by Vasilieva et al (2005). The researchers studied the plasma levels of T3 and T4 in 142 children with CP and other neurological pathologies. They showed that there was a significant increase in T3 and T4 in many cases compared to the healthy controls. The changes in thyroid hormone content depended on the patient's age and severity of the pathological condition (Vasilieva et al., 2005). Mild thyroid dysfunction, with elevated TSH that was below the clinical threshold (5-15 mIU/L), was found in boys with CP. However, it may not be associated with their impaired psychomotor development.

We found no significant correlation between Dkk1 and BMI or osteoblast or osteoclast activation markers in the CP group. However, there was a moderate positive relationship between Dkk1 and calcium in the control group. Notably, this study was conducted in children at an early age (5-12 years), and during this stage of human life, bone growth is highly active in favor of net bone formation rather than bone resorption until the optimum bone mass (peak bone mass) is achieved (Davies et al., 2005). The prolonged absence of mechanical unloading prior to physical therapy could be a reason for the Dkk1 serum increase.

In summary, our study showed a nonsignificant increase in the Dkk1 levelin boys with $\mathrm{CP}$, parallel to an increase in bone formation markers, P1NP and B-ALP. Measurement of serum Dkk1 levels may be useful predictive tool in the study of $\mathrm{CP}$ children who complain of bone fragility. Moreover, Dkk1 may in part mediate bone loss among patients experiencing weight loss.

The strength of this project is that Dkk1 could be used as a potential diagnostic marker in $\mathrm{CP}$ patients with rickets and osteoporosis. Further research is needed to determine the specific role Dkk1 plays in the bones of children with $\mathrm{CP}$. The mechanisms for weight loss-induced bone loss could lead to more effective management to avoid bone loss, especially in physically disabled children who suffer from rickets and osteoporosis.

\section{Acknowledgments}

The authors would like to thank the staff and nurses of the Disabled Children's Association in Jeddah, Kingdom of Saudi Arabia. Special thanks to the parents of the children who volunteered in this study. Special thanks to Prof. Mohammed Saleh Aradwi for providing the labs and equipment in the Centre of Excellence for Osteoporosis Research and Faculty of Medicine, King Abdul Aziz University, Jeddah, Kingdom of Saudi Arabia.

\section{Funding}

This study received funding from King Abdul Aziz City for Science and Technology (number AP-35-230).

\section{Declarations of interest}

The authors have no conflicts of interest relevant to this article to disclose.

\section{Disclosure summary}

The authors have nothing to disclose.

\section{References}

Adami S, Gatti D, Viapiana O, Fiore CE, Nuti R, Luisetto G, Ponte M, Rossini M, Bonturno Study Group (2008) Physical activity and bone turnover markers: a cross-sectional and a longitudinal study. Calcified Tissue International 83: 388-392. doi:10.1007/s00223-008-9184-8.

Aguirre JI, Plotkin LI, Stewart SA, Weinstein RS, Parfitt AM, Manolagas SC, Bellido T (2006) Osteocyte apoptosis is induced by weightlessness in mice and precedes osteoclast recruitment and bone loss. Journal of Bone and Mineral Research 21: 605-615. doi:10.1359/jbmr.060107. 
AL-Balawi ZA, Sonbol HS, Aradwi MS (2017) Determination of Dickkopf-1 in serum of physically disabled Saudi girls and its correlation with BMI and bone turnover markers. Journal of American Science 13: 39-45.

Ardawi MS , Maimani AA , Bahksh TA , Rouzi AA , Qari MH , Raddadi RM (2010) Reference intervals of biochemical bone turnover markers for Saudi Arabian women: a cross-sectional study. Bone 47:804-814

Aronson E, Stevenson SB (2012) Bone health in children with cerebral palsy and epilepsy. Journal of Pediatric Health Care 26: 193-199. doi:10.1016/j.pedhc.2010.08.008.

Azcue MP, Zello GA, Levy LD, Pencharz PB (1996) Energy expenditure and body composition in children with spastic quadriplegic cerebral palsy. Journal of Pediatrics 129: 870-876. doi:10.1016/S0022-3476(96)70031-8.

Baroncelli GI, Bertelloni S, Sodini F, Saggese G (2005) Osteoporosis in children and adolescents: etiology and management. Pediatric Drugs 7: 295-323. doi:10.2165/00148581200507050-00003.

Betts A M, Clark TH, Yang J, Treadway JL, Li M, Giovanelli M A,Abdiche Y, Stone DM, \&Paralkar V M (2010). The application of target information and preclinical pharmacokinetic/pharmacodynamic modeling in predicting clinical doses of a Dickkopf-1 antibody for osteoporosis. Journal of Pharmacology and Experimental Therapeutics, 333(1), 2-13.

Bonewald LF (2011) The amazing osteocyte. Journal of Bone and Mineral Research 26: 229-238. doi:10.1002/jbmr.320.

Bonewald LF, Johnson ML (2008) Osteocytes, mechanosensing and Wnt signaling. Bone 42: 606-615. doi:10.1016/j.bone.2007.12.224.

Buehlmeier J, Frings-Meuthen P, Mohorko N, Lau P, Mazzucco S, Ferretti JL, Biolo G, Pisot R, Simunic B, Rittweger J (2017) Markers of bone metabolism during 14 days of bed rest in young and older men. Journal of Musculoskeletal and Neuronal Interactions 17: 399-408.

Butler JS, Queally JM, Devitt BM, Murray DW, Doran PP, O'Byrne JM (2010) Silencing Dkk1 expression rescues dexamethasone-induced suppression of primary human osteoblast differentiation. BMC Musculoskeletal Disorders 11: 210. doi:10.1186/1471-2474-11-210.

Choi HJ, Park H, Lee HW, Kwon YG (2012) The Wnt pathway and the roles for its antagonists, DKKS, in angiogenesis. IUBMB Life 64: 724-731. doi:10.1002/iub.1062.
Civitelli R, Armamento-Villareal R, Napoli N (2009) Bone turnover markers: understanding their value in clinical trials and clinical practice. Osteoporosis International 20: 843-851. doi:10.1007/s00198-009-0838-9.

Dahl M, Thommessen M, Rasmussen M, Selberg T (1996) Feeding and nutritional characteristics in children with moderate or severe cerebral palsy. Acta Paediatrica 85: 697-701. doi:10.1111/j.1651-2227.1996.tb14129.x.

Dahlseng MO, Finbråten AK, Júlíusson PB, Skranes J, Andersen G, Vik T (2012) Feeding problems, growth and nutritional status in children with cerebral palsy. Acta Paediatrica 101: 92-98. doi:10.1111/j.1651-2227.2011.02412.x.

Davies JH, Evans BAJ, Gregory JW (2005) Bone mass acquisition in healthy children. Archives of Disease in Childhood 90: 373-378. doi:10.1136/adc.2004.053553.

Delalić A, Kapidžić-Bašić N, Glinac A (2014) Body mass index in cerebral palsy patients with various motor severities. Paediatrics Today 10: 95-103. doi:10.5457/p2005-114.95.

Ray S, Khassawna TE, Sommer U, Thormann U, Wijekoon N, Lips K, Heiss C, Alt V (2017) Differences in expression of Wnt antagonist Dkk1 in healthy versus pathological bone samples. Journal of Microscopy 265: 111-120. doi:10.1111/jmi.12469

Diwan J, Diwan S, Bansal A (2014) Body mass index in children with cerebral palsy. National Journal of Integrated Research in Medicine 5: 40-45.

Dovjak P, Dorfer S, Föger-Samwald U, Kudlacek S, Marculescu R, Pietschmann P (2014) Serum levels of sclerostin and dickkopf1: effects of age, gender and fracture status. Gerontology 60: 493501. doi:10.1159/000358303.

Duran I, Schulze J, Martakis K, Stark C, Schoenau E (2018) Diagnostic performance of body mass index to identify excess body fat in children with cerebral palsy. Developmental Medicine and Child Neurology 60: 680-686. doi:10.1111/dmcn.13714.

Galli C, Piemontese M, Lumetti S, Manfredi E, Macaluso GM, Passeri G (2012) The importance of WNT pathways for bone metabolism and their regulation by implant topography. European Cells and Materials 24: 46-59. doi:10.22203/eCM.v024a04.

Gifre L, Vidal J, Carrasco JL, Filella X, Ruiz-Gaspà S, Muxi A, Portell E, Monegal A, Guañabens N, Peris P (2015) Effect of recent spinal cord injury on wnt signaling antagonists (sclerostin and dkk-1) and their relationship with bone loss. A 12-month prospective study. Journal of Bone and Mineral Research 30: 1014-1021. doi:10.1002/jbmr.2423. 
Goksen D, Darcan S, Coker M, Kose T (2006) Bone mineral density of healthy Turkish children and adolescents. Journal of Clinical Densitometry 9: 84-90. doi:10.1016/j.jocd.2005.08.001.

Henderson RC, Lark RK, Gurka MJ, Worley G, Fung EB, Conaway M, Stallings VA, Stevenson RD (2002) Bone density and metabolism in children and adolescents with moderate to severe cerebral palsy. Pediatrics 110: e5. doi:10.1542/peds.110.1.e5.

Henriksen K, Christiansen C, Karsdal MA (2015) Role of biochemical markers in the management of osteoporosis. Climacteric 18: 10-18. doi:10.3109/13697137.2015.1101256.

Hillesund E, Skranes J, Trygg KU, Bøhmer T (2007) Micronutrient status in children with cerebral palsy. Acta Paediatrica 96: 1195-1198. doi:10.1111/j.1651-2227.2007.00354.x.

Hunter D, De Lange M, Snieder H, MacGregor AJ, Swaminathan R, Thakker RV, Spector TD (2001) Genetic contribution to bone metabolism, calcium excretion, and vitamin $\mathrm{D}$ and parathyroid hormone regulation. Journal of Bone and Mineral Research 16: 371-378. doi:10.1359/jbmr.2001.16.2.371.

Hurvitz EA, Green LB, Hornyak JE, Khurana SR, Koch LG (2008) Body mass index measures in children with cerebral palsy related to gross motor function classification: a clinic-based study. American Journal of Physical Medicine and Rehabilitation 87: 395-403. doi:10.1097/PHM.0b013e3181617736.

Ke HZ, Richards WG, Li X, Ominsky MS (2012) Sclerostin and Dickkopf-1 as therapeutic targets in bone diseases. Endocrine Reviews 33: 747-783. doi:10.1210/er.2011-1060.

Kim W, Lee SJ, Yoon YK, Shin YK, Cho SR, Rhee Y (2015) Adults with spastic cerebral palsy have lower bone mass than those with dyskinetic cerebral palsy. Bone 71: 89-93.

Klein-Nulend J, Bakker AD, Bacabac RG, Vatsa A, Weinbaum S (2013) Mechanosensation and transduction in osteocytes. Bone 54: 182-190. doi:10.1016/j.bone.2012.10.013.

Li X, Grisanti M, Fan W, Asuncion FJ, Tan HL, Dwyer D, Han CY, Yu L, Lee J, Lee E, Barrero M, Kurimoto P, Niu QT, Geng Z, Winters A, Horan T, Steavenson S, Jacobsen F, Chen Q, Haldankar R, Lavallee J, Tipton B, Daris M, Sheng J, Lu HS, Daris K, Deshpande R, Valente EG, Salimi-Moosavi H, Kostenuik PJ, Li J, Liu M, Li C, Lacey DL, Simonet WS, Ke HZ, Babij P, Stolina M, Ominsky MS, Richards WG (2011) Dickkopf1 regulates bone formation in young growing rodents and upon traumatic injury. Journal of Bone and Mineral Research 26: 26102621. doi:10.1002/jbmr.472.
Lin PP, Henderson RC (1996) Bone mineralization in the affected extremities of children with spastic hemiplegia. Developmental Medicine and Child Neurology 38: 782-786. doi:10.1111/j.14698749.1996.tb15112.x.

Mansour MMHK, Alhadidi KM (2012) Vitamin D deficiency in children living in Jeddah, Saudi Arabia. Indian Journal of Endocrinology and Metabolism 16: 263-269. doi:10.4103/22308210.93746 .

Melunovic M, Hadzagic-Catibusic F, Bilalovic V, Rahmanovic S, Dizdar S (2017) Anthropometric parameters of nutritional status in children with cerebral palsy. Materia Socio-Medica 29: 6872.doi:http://dx.doi.org.sdl.idm.oclc.org/10.5455/msm.2017.29.

Ministry of Health Saudi Arabia (2016) Musculoskeletal system diseases/ disability: reasons, types, treatment and rehabilitation/ what is disability? http://www.moh.gov.sa.

Morvan F, Boulukos K, Clément-Lacroix P, Roman Roman S, Suc-Royer I, Vayssière B, Ammann P, Martin P, Pinho S, Pognonec P, Mollat P, Niehrs C, Baron R, Rawadi G (2006) Deletion of a single allele of the Dkk1 gene leads to an increase in bone formation and bone mass. Journal of Bone and Mineral Research 21: 934-945. doi:10.1359/jbmr.060311.

Niida A, Hiroko T, Kasai M, Furukawa Y, Nakamura Y, Suzuki Y, Sugano S, Akiyama T (2004) DKK1, a negative regulator of Wnt signaling, is a target of the $\beta$-catenin/TCF pathway. Oncogene 23: 8520-8526. doi:10.1038/sj.onc.1207892.

Pascoe J, Thomason P, Graham HK, Reddihough D, Sabin MA (2016) Body mass index in ambulatory children with cerebral palsy: a cohort study. Journal of Paediatrics and Child Health 52: 417-421. doi:10.1111/jpc.13097.

Quarles LD (2008) Endocrine functions of bone in mineral metabolism regulation. Journal of Clinical Investigation 118: 3820-3828. doi:10.1172/JCI36479.

Rachner TD, Thiele S, Göbel A, Browne A, Fuessel S, Erdmann K, Wirth MP, Fröhner M, Todenhöfer T, Muders MH, Kieslinger M, Rauner M, Hofbauer LC (2014) High serum levels of Dickkopf1 are associated with a poor prognosis in prostate cancer patients. BMC Cancer 14: 649. doi:10.1186/1471-2407-14-649.

Ralston SH, Galwey N, MacKay I, Albagha OM, Cardon L, Compston JE, Cooper C, Duncan E, Keen R, Langdahl B, McLellan A, O'Riordan J, Pols HA, Reid DM, Uitterlinden AG, Wass J, Bennett ST (2005) Loci for regulation of bone mineral density in men and women identified by genome wide linkage scan: the FAMOS study. Human Molecular Genetics 14: 943951. doi:10.1093/hmg/ddi088. 
Rauchenzauner M, Schmid A, Heinz-Erian P, Kapelari K, Falkensammer G, Griesmacher A, Finkenstedt G, Högler W (2007) Sex- and age-specific reference curves for serum markers of bone turnover in healthy children from 2 months to 18 years. Journal of Clinical Endocrinology and Metabolism 92: 443-449. doi:10.1210/jc.2006-1706.

Holguin N, Brodt MD, Silva MJ (2016) Activation of Wnt Signaling by Mechanical Loading Is Impaired in the Bone of Old Mice. Journal of bone and mineral research : the official journal of the American Society for Bone and Mineral Research 12:22152226. doi:10.1002/jbmr.2900.

Robling AG, Turner CH (2009) Mechanical signaling for bone modeling and remodeling. Critical Reviews in Eukaryotic Gene Expression 19: 319-338. doi:10.1615/CritRevEukarGeneExpr.v19.i4.50.

Roessler E, Du Y, Glinka A, Dutra A, Niehrs C, Muenke M (2000) The genomic structure, chromosome location, and analysis of the human DKK1 head inducer gene as a candidate for holoprosencephaly. Cytogenetics and Cell Genetics 89: 220-224. doi: $10.1159 / 000015618$.

Santos A, Bakker AD, Klein-Nulend J (2009) The role of osteocytes in bone mechanotransduction. Osteoporosis International 20: 1027-1031.

Sato Y, Fujimatsu Y, Kikuyama M, Kaji M, Oizumic K (1998) Influence of immobilization on bone mass and bone metabolism in hemiplegic elderly patients with a long-standing stroke. Journal of the Neurological Sciences 156: 205-210. doi:10.1016/S0022510X(98)00041-0.

Shao YC, Wei Y, Liu JF, Xu XY (2017) The role of Dickkopf family in cancers: from Bench to Bedside. American Journal of Cancer Research 7: 1754-1768.
Shin YK, Yoon YK, Chung KB, Rhee Y, Cho SR (2017) Patients with non-ambulatory cerebral palsy have higher sclerostin levels and lower bone mineral density than patients with ambulatory cerebral palsy. Bone 103: 302-307. doi:10.1016/j.bone.2017.07.015.

Sullivan PB, Lambert B, Rose M, Ford-Adams M, Johnson A, Griffiths P (2000) Prevalence and severity of feeding and nutritional problems in children with neurological impairment: Oxford Feeding Study. Developmental Medicine and Child Neurology 42: 674-680. doi:10.1017/S0012162200001249.

Szulc P, Delmas PD (2008) Biochemical markers of bone turnover: potential use in the investigation and management of postmenopausal osteoporosis. Osteoporosis International 19: 1683-1704. doi:10.1007/s00198-008-0660-9.

Tasdemir HA, Buyukavci M , Akcay F, Polat P , Yildiran A, Karakelleoglu C (2001) Bone mineral density in children with cerebral palsy. Pediatrics International 43: 157-160. doi:10.1046/j.1442-200x.2001.01352.x.

Tella SH, Gallagher JC (2014) Biological agents in management of osteoporosis. European Journal of Clinical Pharmacology 70: 1291-1301. doi:10.1007/s00228-014-1735-5.

Unay B, Sarici SU, Vurucu S, Inanç N, Akin R, Gökçay E (2003) Evaluation of bone mineral density in children with cerebral palsy. Turkish Journal of Pediatrics 45: 11-14.

Vasilieva EM, Shor TA, Poddubnaia AE (2005) Changes of the thyroid hormone status in children with cerebral palsy and other neurological pathology. Zhurnalnevropatologiiipsikhiatriiimeni S.S. Korsakova (Moscow, Russia: 1952) 105: 10-14.

Verrotti A, Coppola G, Parisi P, Mohn A, Chiarelli F (2010) Bone and calcium metabolism and antiepileptic drugs. Clinical Neurology and Neurosurgery 112: 1-10. doi:10.1016/j.clineuro.2009.10.011. 